\title{
Use of conjoint analysis to determine the impact of logotype colour, and the type, duration and price of a street performance on consumer purchase decisions
}

\section{ABSTRACT}

The aim of our research was to determine how colour impacts the effectiveness of a logotype for a particular activity and which colour used is strong, stable, associative and "playful", and thus the most appropriate for presenting a selected activity. For the purpose of this research, a logotype for a circus artist was designed using four colour variations, while conjoint analysis was used to identify the colour preference of a specific logotype. Besides colour, three additional attributes were chosen: the type, duration and price of a performance. Three or four levels were specified for every attribute. The results of the survey showed that colour is the not the most important of the four attributes, but that it does have a certain effect on a customer's decision. In the analysis, most respondents choose the red logotype, an outdoor performance, and the longest duration and the lowest price of a performance. The most important of the four attributes for respondents was the price of a performance, followed by the duration of a performance, the content/type of a performance and finally the colour of the associated logotype. The preference of respondents was improved by testing combinations of the four attributes and levels, where the colour blue was replaced with red. The research opens possibilities for further research regarding the impact of colours on subconscious decisions.

\author{
Maja Piko ${ }^{1}$, Jani Toros², \\ Urška Stankovič Elesini ${ }^{1}$ \\ ${ }^{1}$ University of Ljubljana, Faculty of \\ Natural Sciences and Engineering, \\ Department of Textiles, \\ Graphic Arts and Design, \\ Ljubljana, Slovenia \\ ${ }^{2}$ Innovative Management Institute, \\ Ljubljana, Slovenia
}

Corresponding author: Urška Stankovič Elesini e-mail:

urska.stankovic@ntf.uni-lj.si

First recieved: 25.08.2017. Accepted: 20.11.2017.

\section{KEY WORDS}

logotype, colour, conjoint analysis, attributes, colour preference

\section{Introduction}

All over the world, jugglers, magicians, illusionists, acrobats, dancers, actors, etc. carry out a variety of performances, not only in commercial theatres and circuses, but also on town streets. Depending on the type and quality of their shows, their creative and innovative approach, and the duration and impressiveness of performances, etc., those artists are more or less successful. To communicate with their target audience/customers, they require a clear and understandable identity that is in many ways similar to a corporate identity. Corporate identity has a significant impact on the marketing of products and services (Repovš, 1995). Successful communication with customers generates market recognition, meaning that the information communicated must be unique and clear (Wiedemann, 2009) and must send the right message (Adams, 2004). Because people are visual beings, visual images have a significant impact on our purchase decisions (Cato, 2010). It is thus important to use artistic elements and variables effectively (Butina, 2000). A visual message must appeal to the target audience and must also be "invisible" to the user (Visocky O 'Grady \& Visocky O 'Grady, 2008). Visual language 
usually comprises different elements by giving a product or service an emotional note (Bonnici, 1999). The story and feelings evoked by colours, forms and images create the desire for a real experience. As Gardner (2010) determined, even we are rationally aware that we will not get the exact image created in our mind by purchasing a product or service, but we nevertheless wish to satisfy our senses. Such thinking comes naturally. The first impression that companies create for their products or services is thus crucial. Corporate identity is like the flag or coat-of-arms of a company, as it is a visual presentation of an idealised identity. It presents the identity of the company in symbols, and is the strongest weapon in strategic terms for the successful equivalent exchange of a product or service with customers.

An important part of a corporate identity is the associated brand. It represents the synergistic activity of people's perception of a company's customer service, reputation, advertising and logotype. A logotype is visual element of a corporate identity and represents an important and the most complex element of a corporate identity. Knowledge of the mission, strengths, philosophy, objectives and culture of a company is required for a successful logotype (Repovš, 1995). The values of a company are communicated to customers (and to employees, shareholders, investors, the market, etc.) via a logotype (Morgan, 1999). If a logotype is not properly designed, it can have a negative impact on a company (Murphy \& Rowe, 1988). The properties of a good logotype are simplicity, easiness, timelessness, versatility, appropriateness and quick recall by consumers. The rule for logotypes is 'less is more'. A logotype is not a brand, but rather a form of a brand's expression; it has a significant impact because it represents a promise. A logotype must be something completely new, but not overly classical, so it might remain popular for a longer period of time (Wiedemann, 2005). In research performed by Cowin (2011), six world famous logotypes of American companies (Apple, McDonald's, Nike, Pepsi, Shell and Starbucks) were analysed. It was determined that six elements are important in designing a logotype: focus on the future, identification with observers, instant recognition and distinction, coherence through development, openness to changes and the true presentation of a company. Macnab (2008) suggests that a logotype should be natural and harmonious, comprising simple numbers and forms, and more focused on quality than on quantity. The symbols used must be meaningful and recognisable, regardless of the spoken language. The elements of a logotype can be pictorial, typographic or a combination of both. However, thought must be given to the selection of all elements. The appropriate colours must also be chosen (Walch \& Hope, 1995), as they may evoke both positive and negative feelings in people (Trstenjak, 1996).

Chen and Chen (2007) claim that, besides the symbols and text used, colour is also a function of communica- tion, identification and symbolism, and that its meaning is often forgotten. The right colour or colour combination of a logotype appeals to the appropriate target audience. An example is the preferred use of the colour red in the logotypes of fast-food companies (Figure 1). The colour red in a logotype catches the attention of customers, but is not pleasing to look at for an extended period, meaning customers soon leave the restaurant and leave space for others. (Chiazzari, 2000).
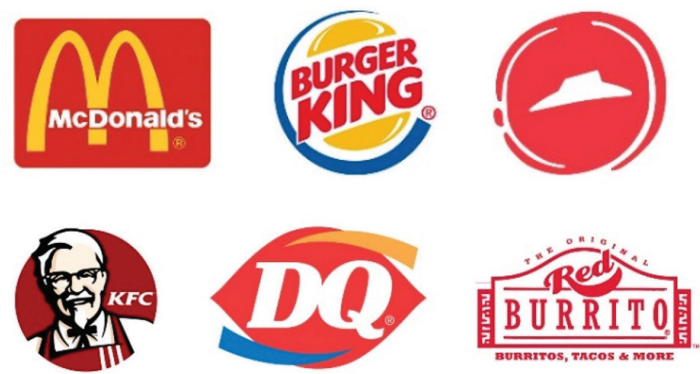

» Figure 1: Logotypes of fast-food companies

Colours can become "traditional" for some products, even if they are not typically connected with them (i.e. the violet colour used for Milka chocolate products). (Holtzschule, 2011).

The colour preference in a particular logotype depends on the message that the logotype communicates. In our research, we focused on a circus artist and the services he offers thus logotypes of different artists, events and organisations involved in similar activities were collected and analysed (Figure 2).

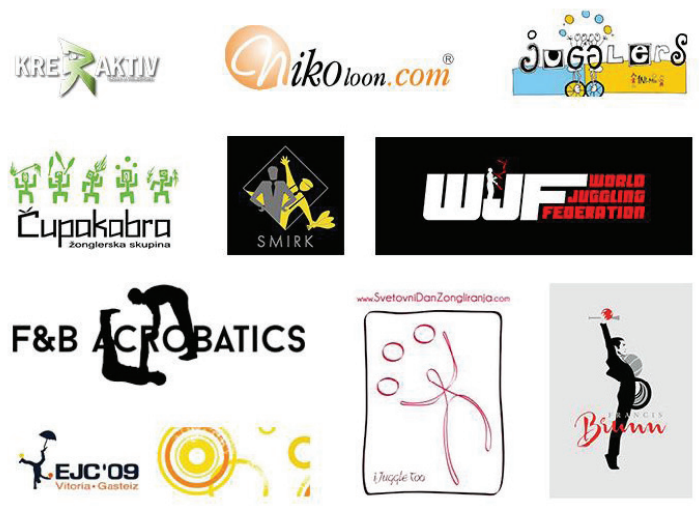

» Figure 2: Examples of logotypes representing circus art

As can be seen from Figure 2, some logotypes are rather classical (e.g. the logotype of Francis Brunn), while others radiate joy (e.g. Jugglers). Some are flexible, lively and dynamic, but at the same time have a serious and professional appearance (e.g. EJC'09). Some logotypes do not present the associated activity with enough clarity (e.g. Kreaktiv), while others associate clearly with the activity (e.g. Nikoloon.com). Some logotypes have too many details (e.g. Čupakabra) or the figures cover the 
inscription (e.g. F\&B Acrobatics), while some are too simple and already frequently seen (e.g. World Juggling Day). The colours in some logotypes are too heavy (e.g. WJF) or unbalanced (e.g. SMIRK). The logotypes for circus art use three colours to create a dominant effect: light-blue, red and yellow. Light-blue creates a feeling of trust and loyalty, and is a colour that represents honour, quality and skills. Red represents passion, reliability, hard work and success. It is the colour of power and vitality, but also of anger (Eisman, 2006). Unlike red, yellow radiates outwards; it is a colour that represents energy, vitality, intellectual power and curiosity (Chiazzari, 2000).

A logotype in our research was designed in four different colours. The aim of the research was to determine 1) how important the colour element of a logotype is in the marketing of an artist performance: and 2) whether specific colours typically have a different impact on a logotype's effectiveness.

\section{Methodology}

The research was divided into two parts. During the first part, a logotype was designed for a circus artist, as shown below. For the purpose of further analysis, we created the logotype in four different colours. In the second part of the research, conjoint analysis was used to determine the preference of respondents with regard to four chosen attributes, and to determine the impact of four different colours on the effectiveness of the logotype.

\section{Preliminary analysis: basis for designing the logotype}

For the purpose of our research, we designed a logotype for the services of a circus artist who is already active on the Slovenian market. Based on an analysis of the above logotypes (Figure 2), a conversation with the chosen circus artist and a viewing of his performances, the following starting points were established for designing a logotype that represents the artist's main activity of juggling:

- a professional, funny juggler with

an excellent technique;

- performances that create an experience of fun, laughter, joy and relaxation, while also offering professional juggling tricks;

- a serious approach to work, accompanied by playful exploration;

- personal traits of the artist: kind, staunchly determined, simple and flexible; circus art makes him happy; he is able to perform every day and wants to please everyone; - the artist's motto is: "Life is in my hands";

- the essential elements of the artist's brand include admiration, enthusiasm, joy, childishness, playful- ness, beauty, patterns or images created through juggling, and appreciation of the audience; and

- the artist's target audience comprises parents and children requiring a circus-artistic show for special events.

The research focused on the service of artistic performances. This service is usually more difficult to understand and present as a product because the human factor is an important element in the co-creation of the service. For this reason, the human factor must be taken into account accordingly and presented to future users in graphic images.

\section{Logotype sample design}

According to our preliminary analysis, the circus artist's logotype must present an image of liveliness, and at the same time seriousness and professionalism. The logotype should be very simple, while communicating a great deal about the artist and his work. From several ideas and sketches, an orb lying in an upturned palm in a rectangular form was chosen (Figure 3). The sketch was transferred into the Adobe Illustrator programme, where minimal transformations were performed, together with colour selection and typography. The selected typography was minimalistic, with a serious yet lively and playful form: serious because the logotype must present an air of professionalism, and lively because the artist's performances are mostly meant for children. The appropriate fonts Alex-brush in Print-Clearly were chosen using the Font Squirrel web application (Font Squirrel, Wilmington, Germany) and added to the logotype.
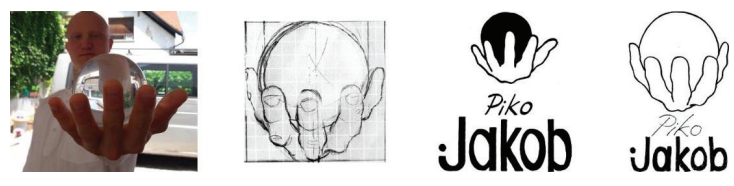

» Figure 3: From left to right orb prop, orb in square, first variation of the logotype, simplified logotype

The final logotype was first created using a black and white combination. In our continuing research, four different colour combinations were chosen: two warm (yellow and red) and two cold (blue and green) (Figure 4). Those logotypes were used for our conjoint analysis.

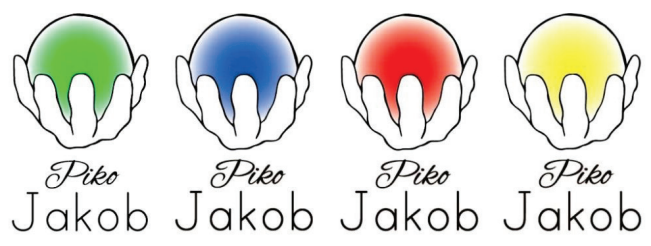

» Figure 4: Final logotype in four colour variations

An orb lying in an upturned palm with all five fingers visible was chosen for the logotype. That orb represents 
an element of the artist's performance, i.e. a contact ball. The illustration of the logotype tells us that the artist creates magic in his performances using hand skills. It is a simple logotype that presents a major concept. The hand is half open, which supports the artist's motto "Life is in my hands". It is also opened to the target audience, offering them a ball, by which the artist positively and confidently offers an experience. The logotype is reminiscent of a light bulb that illuminates as an idea because our artist always has a head full of fun ideas.

A serious font, in combination with a white-gloved hand, represents the professionalism of the artist's offer. Most people present an offer as it is. However, the logotype that we created makes the artist's offer stand out from the competition. The logotype communicates the fact that the artist's performances emphasise art and technique. The illustration represents his art, while the straight lines symbolise his professionalism. The chosen font curves complement the curves of the illustration. The straight lines complement the lines of the rectangle, which surrounds the sculptured illustration, while the convolutions of the golden-cut font express happiness. The logotype was designed for use on props, gift programmes and promotional materials, and on the artist's website and business cards.

\section{Conjoint analysis: creating a questionnaire and collecting data}

An advanced and scientifically justified conjoint analysis was used to prove the two aforementioned assumptions. Although conjoint analysis is most frequently used for market research, it is also useful in other fields where customer preferences are measured (i.e. for designing products and services, advertisement, segmentation, market share, etc.). Conjoint analysis allows us to determine which properties must be focused on during the development of a product or service (Baker \& Hart, 1999; Sawtooth Software, 2017). Every product has several properties (hereinafter: attributes), such as brand, colour and packaging, or speed, fuel consumption, trunk size, origin, etc. for a car. Conjoint analysis is used to measure product preferences that a customer ascribes to different levels of attributes (Kotler, 2004). It is used assuming that a consumer's purchase decision involves a comparison of the different attributes of a product or service, and that they see different attributes as more or less important. A product or service is integrally shown by conjoint analysis, as respondents compare and evaluate all elements at chosen platforms simultaneously. The "unlimited" combinations that are generated in the analysis also represent an opportunity to predict new directions for a product or service on the market.

Conjoint analysis can also be used in the field of graphic design, particularly for researching the preferentiality of individual elements of packaging. In their research, Ares and Deliza (2010) used conjoint analysis in an attempt to determine the impact of the form and colour of a package on consumer expectations in a case involving dairy desserts. Grobelny and Michalski (2015) also used conjoint analysis in their attempt to identify persons' attitudes toward digital graphical information regarding various types of smartphone's virtual package designs.

Four main attributes were chosen for the purpose of our conjoint analysis:

- colour of the logotype: the colour of the logotype was the main subject of our research, as its impact on respondents' purchase decisions was researched;

- the content of the performance: the circus artist offers several types of performances to his target audience, while our aim was to determine which performance is preferred most;

- duration: the duration of performances can be of varying length. It is thus important to know how much time the target audience is willing to dedicate to watching an individual performance; and

- price: price is frequently an important element in the selection of a service or product, and was thus included as an attribute for the purpose of conjoint analysis.

Three or four levels were defined for each attribute, as seen in Table 1. Four levels were defined for logotype colour and type of performance, while three levels were defined for the duration and price of a performance. It is possible to form 144 different combinations $(4 \times 4 \times 3$ $\times 3$ ) from the selected attributes and associated levels.

\section{Table 1}

Attributes and levels of service rendered by the circus artist

\begin{tabular}{|c|c|c|c|c|}
\hline Level & $\begin{array}{c}\text { Logotype } \\
\text { colour }\end{array}$ & $\begin{array}{c}\text { Performance } \\
\text { content }\end{array}$ & $\begin{array}{c}\text { Duration of } \\
\text { performance } \\
\text { [min] }\end{array}$ & $\begin{array}{c}\text { Price of } \\
\text { performance } \\
\text { [EUR] }\end{array}$ \\
\hline 1st level & Red & $\begin{array}{c}\text { Outdoor } \\
\text { performance }\end{array}$ & 40 & 60 \\
\hline 2nd level & Green & Street theatre & 30 & 70 \\
\hline 3rd level & Yellow & $\begin{array}{c}\text { Children's } \\
\text { entertainment }\end{array}$ & 20 & 80 \\
\hline 4th level & Blue & $\begin{array}{l}\text { Stage per- } \\
\text { formance }\end{array}$ & & \\
\hline
\end{tabular}

The conjoint analysis was carried out using a Sawtooth Software tool (Sawtooth Software, Inc., USA). Choicebased conjoint $(\mathrm{CBC})$ software was used in the scope of the aforementioned tool. During our analysis, three computer-generated combinations of services (generated by a computer taking into account the four attributes and associated levels) and the additional choice, "None of the offered options appeal to me" were given 
to respondents (Figure 5). Respondents were asked to choose the option they prefer most. On the next screen, respondents were given three new combinations and again the choice, "None of the offered options appeal to me". Respondents were again asked to choose the combination they preferred. This was repeated 14 times, with respondents receiving 42 different combinations.

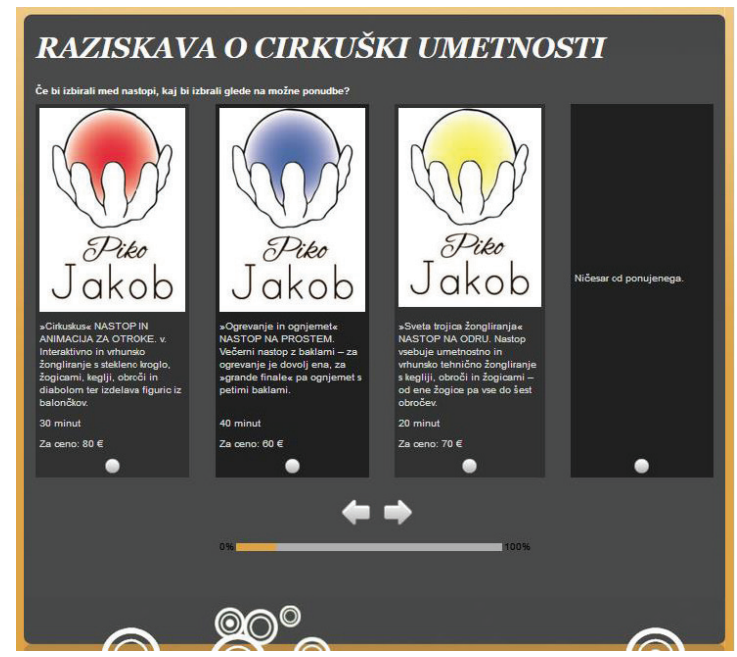

» Figure 5: Three combinations of services + the choice, "None of the offered options appeal to me"

Conjoint analysis was performed online, while the website address for accessing the questionnaire was published on Facebook pages and sent by email.

After the survey was completed, the data were statistically analysed using the Logit software tool, which is part of the Sawtooth Software tool. Logit is a statistical method used for multidimensional regression, meaning it takes into account $x$ and $y$ dimensions, as well as a $z$ dimension. It is used as a diagnostic tool.

At the end of our research, a market simulation tool (SMRT) was used to convert raw conjoint (part-worth utility) data into managerially useful information (simulated market choices). Using SMRT, what-if games were conducted to determine the most preferred logotype colour, performance duration and performance price.

The results of our conjoint analysis are presented in the section 'Results and discussion'.

\section{Target population sample and representativeness of the sample}

The conjoint analysis was performed from a sample of 105 respondents ( $80 \%$ female and $20 \%$ male).

We hoped that the sample of the target population in the survey would mainly comprise potential customers, i.e. parents (usually younger women) who organise birthday parties and other special events, and of course children. According to the percentage of respondents in the younger age group ( $81.9 \%$ of respondents were younger than 30 years and $15.2 \%$ were between the age 31 and 50), the desired target population was achieved. Despite the small sample of respondents, the analysis was primarily performed on the target population, making the sample slightly more representative and thus giving some guidelines for further research.

Because one of the attributes was the price of a performance, the income of respondents was also investigated in the research. The following was determined: the income of $72.4 \%$ of respondents is below the Slovenian average, the income of $20.9 \%$ of respondents is equal to that average, while the income of $6.7 \%$ of respondents exceeds the Slovenian average.

\section{Results and discussion}

\section{Analysis of the results of the impact of individual elements on the offer of a circus artist}

From the results obtained using conjoint analysis, we first determined the importance of individual attributes of the circus performance. It is evident from Figure 6 that of all four attributes affecting a consumer's purchase decision, the most important attribute is price (46.5\%), while less important attributes are performance type (25.3\%) and duration (23.1\%). Least important (5.1\%) is the colour of the logotype.

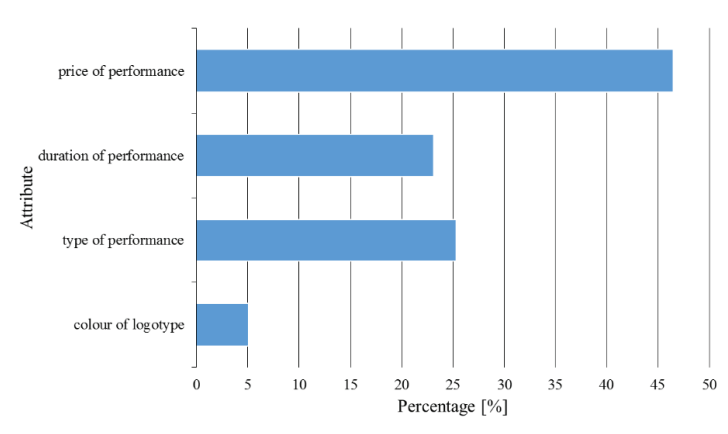

» Figure 6: Average importance of individual attributes

The benefits of an individual offer of the artist were determined through conjoint analysis. The results are calculated as preference levels that show how many times respondents chose or how likely they were to choose an individual level of a specific attribute. The preferences of each level were expressed as coefficients that expand in positive and negative values. The software uses "effects coding", which means that the sum of the coefficients of an individual attribute is 0 .

The first analysed attribute was the price, which was identified as the most important attribute in a purchase 
decision. We can see from the results shown in the Figure 7 that a lower price of $€ 60$ for the performance is preferred (utility value of 98.1), while the higher price of $€ 80$ (utility value of-87.8) is the least preferred. At a price of $€ 70$, the same coefficient amounted-10.2. The fact that most respondents preferred the lower price was probably the consequence of their lower income, as was determined at the beginning of this research.

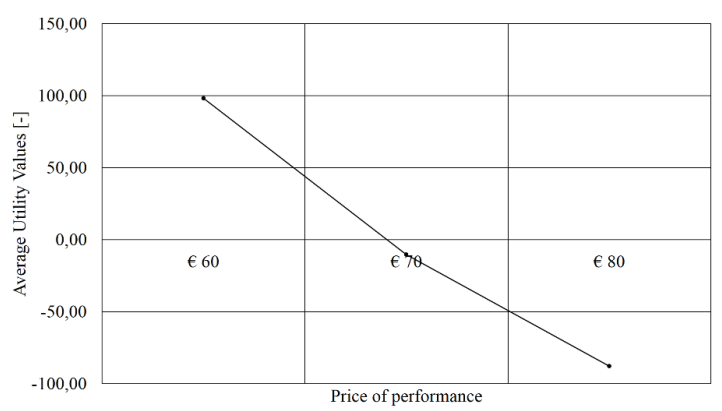

» Figure 7: Preference levels associated with the price of a performance

The type of performance was the second most important attribute in a purchase decision. It is evident from Figure 8 that outdoor performances are preferred most (utility value of 53.3), while less preferred are street theatre performances (utility value of 3.2), children's entertainment (utility value of-8.6) and stage performances (utility value of-47.97). Preference for outdoor performances (and street theatre performances) is probably connected with the existing street performances of circus artist during the summer. It is interesting that the preference levels for children's entertainment and stage performances are low. There are not many offers of circus art for children's birthday parties on the Slovenian market. This could be the reason why children's entertainment is less popular and perhaps too expensive.

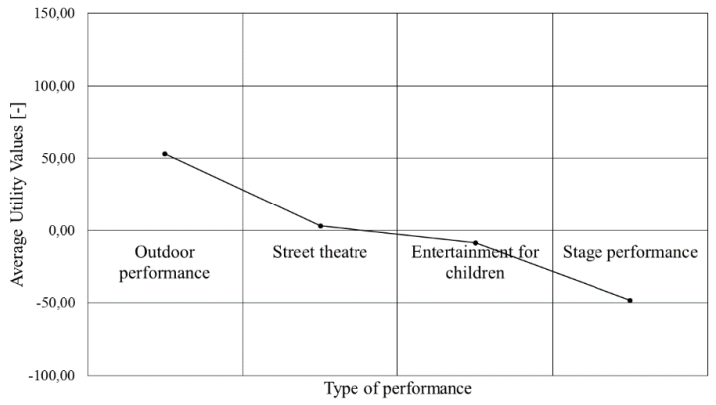

» Figure 8: Preference levels associated with the type of performance

The third most important attribute in a purchase decision is the duration of a performance. Most respondents (Figure 9) preferred a 40-minute performance (utility value of 42.8) and, to a lesser extent, a 30-minute performance (utility value of 6.9), while the fewest respondents chose a 20-minute performance (utility value of-49.7). It is clear from the results that respondents prefer longer circus art performances.

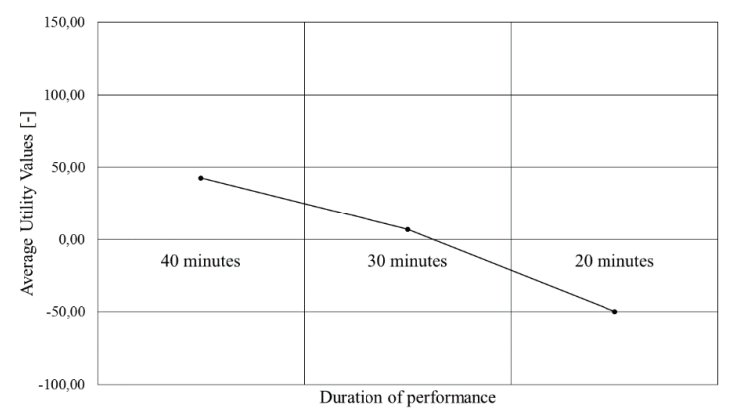

» Figure 9: Preference levels associated with the duration of a performance

The logotype colour was the least important attribute in terms of a purchase decision. The results in Figure 10 show that the colours blue and green are the least popular in a purchase decision associated with a circus art performance. Their coefficients were-9.43 and-6.08, respectively. Yellow was more recognisable as a logotype colour (utility value of 4.63), while red has the greatest impact (utility value of 10.87). Red is thus preferred most in a logotype among the four colours studied, and stands out compared with the other three colours. This result is also consistent with the preliminary analysis, in which red, yellow and light-blue were the prevalent colours in other logotypes identified with circus art.

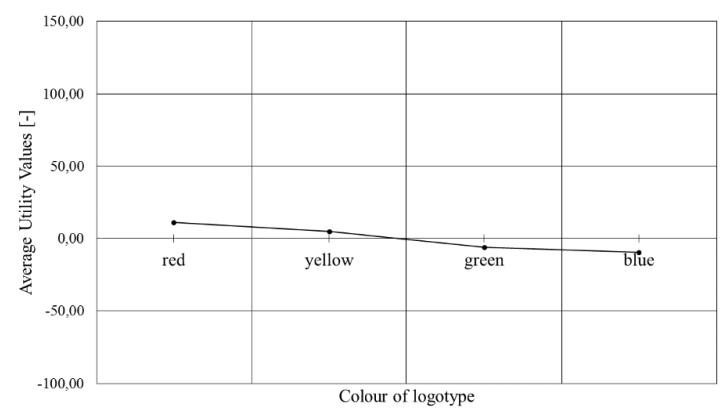

» Figure 10: Preference levels associated with logotype colour

According to the results above, the most important attributes and associated levels that impact a purchase decision are the lowest price of $€ 60$, an outdoor performance, the longest duration of 40 minutes and a red logotype.

\section{Market simulations}

Although the impact of logotype colour on a purchase decision was determined to be low, we were interested in determining whether respondents gave priority to a combination of attributes involving a red logotype. That simulation was performed in the continuation of our research. Three scenarios and estimated shares of preference for fixed alternatives within those scenarios were created for 
simulation purposes. We used this approach to search for the optimal logotype colour based on utility level.

A blue logotype was chosen in the first combination, as seen in Table 2. In this simulation, the first combination includes a blue logotype, a stage performance with a duration of 20 minutes and a price of $€ 70$. The preference of the respondents was $28.47 \%$. The second combination included a green logotype, children's entertainment with a duration of 30 minutes and a price of $€ 60$, resulting in a preference of $40.51 \%$. The third combination included a yellow logotype, a street theatre performance with a duration of 40 minutes and a price $€ 80$. The preference of the latter was $31.02 \%$.

\section{Table 2}

Simulation 1

\begin{tabular}{l|c|c|c|c|c}
\hline & Colour & Performance & Duration & Price & PREFERENCE \\
\hline offer 1 & blue & $\begin{array}{c}\text { stage } \\
\text { performance }\end{array}$ & $20 \mathrm{~min}$ & $€ 70$ & $\mathbf{2 8 . 4 7 \%}$ \\
\hline offer 2 & green & $\begin{array}{c}\text { entertainment } \\
\text { for children }\end{array}$ & $30 \mathrm{~min}$ & $€ 60$ & $40.51 \%$ \\
\hline offer 3 & yellow & street theatre & $40 \mathrm{~min}$ & $€ 80$ & $31.02 \%$ \\
\hline
\end{tabular}

Table 3 shows the same three combinations of offers as in Table 2, except that we changed the colour of the logotype in offer 1 from blue to red. The preference of offer 1 with a red logotype, a stage performance with a duration of 20 minutes and a price of $€ 60$ rose to $29.97 \%$. The preference of the second and the third offers, which include the same elements as in simulation 1 , decreased to $39.74 \%$ and $30.29 \%$, respectively.

\section{Table 3}

Simulation 2

\begin{tabular}{l|c|c|c|c|c}
\hline & Colour & Performance & Duration & Price & PREFERENCE \\
\hline offer 1 & red & $\begin{array}{c}\text { stage } \\
\text { performance }\end{array}$ & 20 min & $€ 70$ & $\mathbf{2 9 . 9 7 \%}$ \\
\hline offer 2 & green & $\begin{array}{c}\text { entertainment } \\
\text { for children }\end{array}$ & 30 min & $€ 60$ & $39.74 \%$ \\
\hline offer 3 & yellow & street theatre & 40 min & $€ 80$ & $30.29 \%$ \\
\hline
\end{tabular}

As is evident from the results above, changing the colour of the logotype from blue to red resulted in an increase in the preference of offer 1 , which suggests that a red logotype has a greater impact on a purchase decision.

\section{Conclusions}

The aim of the research was to determine whether colour, as an element of a logotype, has an impact on effectiveness, and whether it can result in better connectivity, visibility and positive association with the activity that a logotype represents. According to our results, the colour of a logotype has an immaterial impact on a purchase decision. For respondents, the type and the duration of a performance are important, while most important is the price. However, the research showed that typical differences exist between individual colours in terms of their impact on the effectiveness of a logotype. Among the colours included in our analysis (blue, green, yellow and red), red stood out from the others.

Because the sample of the target population was small and mainly oriented to younger parents (primarily women), the given results represent a starting point for further research, as they have raised numerous questions requiring answers. Those questions include (but are not limited to) the following: Because the price of a performance had a significant impact on performance preferences, would it be better to exclude it from the attributes? Is it possible to design a logotype that would have the same effect that price has on a purchase decision?

\section{References}

Adams, S. (2004) Logo design workbook. Gloucester, Rockport publishers.

Ares, G. \& Deliza, R. (2010) Studying the influence of package shape and colour on consumer expectations of milk desserts using word association and conjoint analysis. Food Quality and Preference. 21 (8), 930-937. Available from: doi: 10.1016/j. foodqual.2010.03.006 [Accessed 1st April 2017].

Baker, M. \& Hart, S. (1999) Product Strategy and Management. London, Prentice Hall.

Bardorfer, A. (2002) Conjoint analiza: metoda v tržnem raziskovanju. Ljubljana, Filozofska fakulteta. Available from: http://psy.ff.uni-lj.si/Katedre/PM/Studij/ Conjoint_analiza.ppt [Accessed 10th June 2017].

Bonnici, P. (1999) Visual language, the hidden medium of communication. Crans-Pres-Celigny, RotoVision.

Butina, M. (2000) Mala likovna teorija. Ljubljana, Debora.

Cato, M. (2010) Go logo! A handbook to the art of global branding: 12 keys to creating successful global brands. Beverly, Rockport publishers.

Chen, Y., Wei, B. \& Chen, M. (2007) The effect of colour guidance on design communication. In: Poggenpohl, S. (ed.) Proceedings of IASDRO7: International Association of Societies of Design Research - Emerging Trends in Design Research, 12-15 November 2007, Kowloon, Hong Kong. Kowloon, The Hong Kong Polytechnic University. pp. 1-12.

Chiazzari, S. (2000) Barve. Ljubljana: Slovenska knjiga. 
Cowin, E. (2011) The evolution of U.S. corporate logos a semiotic analysis. Master's thesis. B.A. Florida State University. Available from: http:// etd.fcla.edu/CF/CFE0003597/Cowin_Erica_M_201105_MA.pdf [Accessed 3rd April 2017].

Eisman, L. (2006) Colour: messages and meanings: a Pantone colour resource. Gloucester: Hand Books Press.

Gardner, B. \& Fishel, C. M. (2010). Logolounge master library. Volume 1, 3000 initial and crest logos. Beverly, Rockport Publishers.

Grobelny, J. \& Michalski, R. (2015) The role of background color, interletter spacing, and font size on preferences in the digital presentation of a product. Computers in Human Behavior. 43, 85-100. Available from: doi: 10.1016/j.chb.2014.10.036 [Accessed 15th April 2017].

Holtzschule, L. (2011) Understanding colour: an introduction for designers. Hoboken, Wiley

Kotler, P. (2004) Management trženja. Ljubljana, GV Založba.

Kotler P. and G. Zaltman. (1971) Social Marketing: An Approach to Planned Social Change. Journal of Marketing. 35 (3), 3-12. Available from: https://www.jstor.org/stable/ pdf/1249783.pdf [Accessed 18th April 2017].
Macnab, M. (2008) Decoding Design: Understanding and Using Symbols in Visual Communication. Cincinnati, HOW books.

Morgan, C. L. (1999) Logos: logo, identity, brand, culture. Crans-Pres-Celigny, Rotovision.

Murphy, J. J. \& Rowe, M (1988) How to design trademarks and logos. Oxford, Phaidon.

Repovš, J. (1995) Kako nastaja in deluje učinkovita, tržno usmerjena celostna grafična podoba kot del simbolnega identitetnega sistema organizacij. Ljubljana, Studio Marketing.

Sawtooth Software. (2017) Conjoint analysis Available from: https://www.sawtoothsoftware.com/products/ conjoint-choice-analysis [Accessed 20th June 2017].

Trstenjak, A. (1996) Psihologija barv. Ljubljana, Inštitut Antona Trstenjaka za psihologijo, logoterapijo in antropohigieno.

Visocky O'Grady, J. \& Visocky O'Grady, K. (2008) The information design handbook. Hove, RotoVision.

Walch, M. \& Hope, A. (1995) Living colours: the definitive guide to colour palettes through the ages. San Francisco, Chronicle books.

Wiedemann, J. (ed.) (2005). Logo design. Köln, Taschen. Wiedemann, J. (ed.) (2009) Logo design 2. Köln, Taschen.

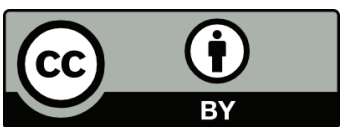

(C) 2017 Authors. Published by the University of Novi Sad, Faculty of Technical Sciences, Department of Graphic Engineering and Design. This article is an open access article distributed under the terms and conditions of the Creative Commons Attribution license 3.0 Serbia (http://creativecommons.org/licenses/by/3.0/rs/). 